\title{
The Dragon, the Knight and the Princess: Folklore in Early Childhood Disaster Education
}

\author{
Maila D. H. Rahiem and Husni Rahim \\ UIN Syarif Hidayatullah, Jakarta, Indonesia \\ https:// orcid.org/0000-0002-5618-2486 \\ https://orcid.org/0000-0003-1797-5018
}

\begin{abstract}
This research investigated the use of folklore in early childhood disaster education. A systematic analysis of the literature was used to evaluate early childhood disaster education. The researchers identified different concepts present in the literature; and examined patterns, parallels, and regularities. The researchers synthesized the principle of folklore use in early childhood disaster education as part of this research. Folklores have a tremendous potential to make early childhood disaster education effective if interpreted, integrated, and demonstrated by science. This work provides a strong foundation for further study into the same research issue by using empirical data or research into how to make folklore an efficient tool for early childhood disaster education.
\end{abstract}

Keywords: folklore; culture; disaster risk reduction; disaster prevention and preparedness; early childhood education

\section{Introduction}

Children often tend to be the most affected and vulnerable to disasters (Kousky, 2016; Tanner, Lazcano, Lussier \& Polack, 2009; Winser et al., 2004). This vulnerability occurs both during and after a disaster. Young children are physically vulnerable to unexpected and chronic disasters due, in part or in full, to adult dependency (Peek, 2008). Disasters often result in the constant disruption of children's lives, from families, schooling, accommodation, health care, friendships and other core areas of their lives; they face the risk of parental separation, relocation, trauma, illness, and death (Fothergill, 2017). Disasters interfere with children's psychological health and social functioning (Norris et al., 2002), cause children to suffer from depression, while a severe trauma could affect them for many years to come in terms of their mental health and wellbeing (Bryant et al., 2018). The psychological effects differ greatly across a vast range of challenges, spanning a long time, and are linked to the nature of the event; most people heal soon, while some progress to psychopathology, including posttraumatic stress disorder (PTSD), severe depression, anxiety disorders, and even addiction problems (Shultz, 2014). Disasters impair the long-term learning ability 
of children (Gibbs et al., 2019). Children typically experience emotional and behavioral issues, nightmares and trouble sleeping, and stress-inflicted anxiety attacks (Somasundaram \& van de Put, 2006).

Children need protection during a disaster, but children do have specific capacities that can lead to efforts by the home and community to minimize the disaster risks and impact (Fothergill, 2017). Initiatives to plan for disasters and mitigate risks can be implemented by people to eliminate long-term social and economic disturbances from the impact of these hazards. Education is regarded as one of the best media to create a society that is ready for disasters. Using education, we can raise awareness and understand the danger among children, teach readiness, and demonstrate how to respond in times of disaster (Twigg, 2003). Children's disaster education initiatives will reinforce disaster preparedness and resilience for both children and families (Torani, Majd, Maroufi, Dowlati \& Sheikhi, 2019).

Curriculum on Disaster Risk Reduction (DRR) can enhance pre-school quality, engage children in DRR programs (Proulx \& Aboud, 2019). It would also increase children's understanding of disaster risks and preparedness in ways that might reduce such disaster risks (Amri, Haynes, Bird \& Ronan, 2018; Johnson, Ronan, Johnston, \& Peace, 2014; Proulx \& Aboud, 2019). Disasters can happen when children are at home or in school, when they are with their family or friends or even alone. It is important to involve children in a disaster rescue plan and ensure they know what to do when or if a dangerous situation occurs. Encouraging children to think about the importance of precautionary action and preparedness can narrow the gap between knowledge and action (Bosschaart, van der Schee, Kuiper \& Schoonenboom, 2016; Faber et al., 2014), and save many young lives. They may not fully understand everything and only comprehend a few points, as per their ability to cognize it. So, it is necessary to determine both what to teach and how to teach children these skills and knowledge.

According to studies conducted in various countries, including Japan, there is a direct link between education, increased risk perception, and students' risk reduction measures (Torani et al., 2019). Disaster lessons are usually integrated into curricula, including science, health, geography, literature and civic education, and are organized according to the students' level. In Indonesia, it is integrated into science, social studies, language, mathematics or even religious studies (Rahiem, 2018). Thirty-nine states in the USA, using the Michigan Model for Health, are integrating disaster preparedness curricula into their School Health Program (Eisman et al., 2020). Natural disasters are addressed in geography lessons in Australia and New Zealand (Duffy, 2014). In the United Kingdom, disaster education is incorporated into textbooks used in science and geography (Sharpe \& Kelman, 2011). In Taiwan, a flood game was introduced to encourage the active learning of players through exploration (Tsai, Wen, Chang \& Kang, 2015). In early childhood settings, Iran's disaster education includes posters, videos, role-plays, exercises, and games (Izadkhah \& Hosseini, 2005); while in the Philippines, teachers use animation videos, songs, and storybooks to teach about disasters and preparedness for disasters (Ani, Daquio \& Aquino, 2015). 
Since the devastating earthquake and tsunami that affected several Asian countries on December 26, 2004, studies have been conducted concerning the use of local culture in disaster prevention programs. Donovan (2010) highlighted the need to investigate the connection between cultural reactions and natural events, otherwise known as 'geoculture.' Bankoff et al. (2013) argued that the root causes of vulnerability lie within the past and progress of our society; therefore, culture has a significant role in society - the relations between the world and our ultimate survival. Jha and Jha (2011) emphasized the importance of indigenous knowledge as a valuable tool that can promote the prevention, preparedness and response to disasters in cost-effective, participatory and sustainable ways. Integrating shared local values, common day-to-day experiences and local communal memories into risk communication strategies and behavioral guidelines can be effective in fostering citizen disaster preparedness (Appleby-Arnold, Brockdorff, Jakovljev \& Zdravković, 2018).

One form of culture that has been discussed as a potential for promoting disaster prevention, preparedness, and responses is folklore. Some work has been conducted that explores how indigenous people survived the destructive tragedy as they learned about tsunamis through stories or songs that are part of their culture. Indigenous people, including Thailand's Moken, Indonesia's Simeulueans and many island groups on the Andaman and Nicobar Islands, were more prepared as they heard from their predecessors about tsunamis. Local knowledge of previous tragedies had been passed down from generation to generation through word of mouth. As a result of this, when the ground began trembling and the tide went out further than ever, the communities were aware of the initial warning signs of earthquake and tsunami, and were able to react accordingly before it was too late. Consequently, they had time to flee inland to higher ground to effectively avoid the direct effects of the disaster (Mercer et al., 2012). Culture has been a factor in the recovery of populations from disasters where, in some cases, culture has served as a deterrent to successful DRR activities (Kulatunga, 2010).

Previous scholars have discussed the importance of early disaster preparedness education for children (Amri et al., 2018; Bosschaart et al., 2016; Faber et al., 2014; Johnson et al., 2014; Proulx \& Aboud, 2019); the role of culture in disseminating a major program such as disaster preparedness and response (Appleby-Arnold et al., 2018; Bankoff, 2013; Donovan, 2010; Jha \& Jha, 2011; Kulatunga, 2010); and how folklore, as one of the sources of local culture, has saved people from disasters as they were more conscious of the hazards of the disasters and also learned what to do when they occur (Mercer et al., 2012) . To the best knowledge of the researchers, scholars have not looked at using folklore in early childhood disaster education. As a result of this gap in existing knowledge, the researchers investigated the idea of using folklore in disaster education in early childhood in this study.

This study is significant in providing an overview of the possibility of implementing a disaster prevention program in the kindergarten. This research is also becoming a preliminary or background study for further exploring the methods and strategies of using folklore in early childhood disaster education. 


\section{Background and Rationale}

The researchers reviewed two sets of literature to establish the conceptual framework within which the study was conducted, namely: early childhood disaster education, and folklore in early childhood education.

\subsection{Early childhood disaster education}

Disaster education, which encompasses disaster risk management, prevention and preparedness measures, is one method for minimizing negative disaster impacts (Mulyasari, Takeuchi \& Shaw, 2011). According to the 2005-2015 Hyogo Framework for Action (United Nations, 2005), the goal of disaster education is to develop a culture of protection and resilience at all levels and reduce the adverse social and economic effects of hazards. Disaster awareness seeks to provide information for individuals and communities to take steps to minimize their vulnerability to disasters (Torani et al., 2019); to mitigate the risk concerning hazardous incidents by helping children and families learn about both exposure and building processes (Ronan, Alisic, Towers, Johnson \& Johnston, 2015).

Education may increase children's perception of risk (Shreve et al., 2014). Disaster education should be specifically discussed as a means of improving child resilience and transmission of information to minimize the risk of disasters in their homes (Torani et al., 2019). Historically, disaster awareness initiatives and the media have provided adults with disaster risk information and ways to protect their families, such as developing family emergency plans, securing home and rental insurance, and storing food, water, and supplies (Mileti, 1995). Specially designed disaster education for children is also required. Children have a unique understanding of risks, and risk perceptions differ according to their age and also gender (Haynes \& Lassa, 2010; Tanner et al., 2009).

Starting education at an early age is suggested because people never forget what they learn at an early age (Torani et al., 2019). According to the United Nations Children's Fund (United Nations Children's Emergency Fund, 2011), children's disaster education services are meant to contribute to a dramatic shift in mentality and attitude and a behavioral improvement towards a more effective disaster reduction approach. If children are presented with the right information and resources and are assisted by adults, they have a greater chance of success. This notion is significant because almost one-third of the world's population is children, and today's solutions can provide long-term impacts to today's children and their societies.

School is the perfect place to prepare pupils for emergency preparedness. Schools have both the physical resources and the personnel to respond to an emergency quickly. They can assist the communities in their efforts to carry out risk analysis and prevention of disasters. In the event of a disaster, schools are well-positioned to play a wide variety of positions as emergency response and relief centers, communication centers, supply depots and hubs of managing partner (Mutch, 2014). Citizens need to be prepared to face disasters and develop detailed educational programs (Torani et al., 2019). 


\subsection{Folklore in early childhood education}

Narratives have been commonly utilized in early years' education as a useful tool for the development of spoken language and literacy. Narratives support the development of literacy, as they help children to learn ideas on how to use language (Maureen, van der Meij \& de Jong, 2018); and to encourage oral skills (Nicolopoulou, Cortina, Ilgaz, Cates \& de Sá, 2015). A narrative can also encourage writing skills by inspiring children to create their own stories, change stories they have read, and even write plays based on popular tales (Cassell, 2004; Nicolopoulou et al., 2015)

Narratives are often considered advantageous due to the support they provide to many other facets of children's growth, including cognitive, physical, emotional, and spiritual. A narrative can power cognitive involvement, critical thinking, and sequencing of stories (Agosto, 2016). It is a powerful tool for promoting selfunderstanding (Lenox, 2000), fairness and diversity (Flewitt, 2017) and promoting inclusive classrooms (Mardell \& Kucirkova, 2017). Narratives are also used frequently in kindergarten for Moral Education (Gunnestad \& Thwala, 2011; Rahim \& Rahiem, 2013; Thambu, 2017; Thompson, 2011; Woodard, 2005). Narratives depict social interactions, friendships and interpersonal relationships. Children also learn from the experiences of the characters in narratives because they offer an image of an individual's life and mind in the form of words (Rahiem, Abdullah \& Krauss, 2020).

Throughout this study, one type of narrative is explored in greater depth, folklore. Dan Ben-Amos famously suggested a definition of folklore as artistic communication in small groups in his seminal essay, "Toward a Definition of Folklore in Context" (Ben-Amos, 1971). A folklore, in its traditional and conventional form, is transmitted orally in most cases and serves as shared tradition-based creations of a particular culture. The manifestations of modern folklores include folk festivals, numerous ensembles of traditional songs and dances, or folklore festivals held around the world (Harvilahti, 2004). Nowadays, folklores are not just found in books, but also include interactive folklore stories or folk-based movies. Ben-Amos (2014) re-conceptualized the meaning of folklore as a specific kind of communication that is distinct in terms of language, image, sound, motion and performance.

Folklore is one of the most popular children's narratives used for language programs in pre-school, and has the power to influence children, teach behavior or good practice and is very similar to the lives of individuals. Researchers observed in many cultures, folklore is associated with stories of dragons, warriors, and princesses. For example, in Indonesia, Balinese, Javanese and Kalimantanese folklores depict an earthquake that is associated with an angered dragon. Another story involves a princess who resided in Mount Rinjani, Lombok, which, when she was disturbed by human attitudes, would lead to a volcanic eruption that destroys nature. A story from Siau, North Sulawesi, involved the main character, Sakeha, who was a brave warrior after a tsunami had occurred and helped everyone that had been affected to recover. Folklore is important in the study of repeatable practices that people deem conventional, connotative, and significant. Folklore often includes ideas that go into creating a culture at different levels, from 
person to nation (Bronner, 2019). Individually and socially, humans are continually in contact with different cultural powers and have a psychological need for tradition, and the reshaping of common practices (Bronner, 2011).

Cultural psychologists theorize that, through interaction with people, material and symbolic artifacts, children grow into cognitively capable adults within their cultural groups (Tomasello, 2009). Folk tales constitute an essential part of the everyday life and traditions of many societies. These are used to reflect and illustrate particular social environments from which children learn social behavior patterns as interactive communicative events. Culture stimulates the mind, while folktales are cultural memories (Olajide, 2010). On the other hand, literacy seeks to make the human mind more functional so that it can most rewardingly solve life's problems. Agbenyega et al. (2017) examined the role of African folklore, specifically Ghanaian folk stories, in the development of child cognition and social life concept formation. They found that traditional oral storytelling can be an important part of early childhood education to improve critical thinking about social life for children.

By using folk stories to construct a dramatization of an imaginary scenario that is culturally prized, the children are on stage acting in the drama, and the audiences are watching the drama. They can see and hear the message within the story despite not having witnessed it themselves directly. This method of delivery helps children switch from a lower mental function to a higher mental, as they form conceptions of values that are central to social life function (Fleer, 2013). It shows that early childhood educators can use folk tale dramas and video with a stimulated recall to help children participate in imaginative recall to give them new insights. What about using folklore to involve children in the imaginary recollection of disaster incidents, giving them new insights into what to do if an emergency occurs so that they can respond with the awareness of the incident and the best way to defend themselves and others? The researchers used this thinking as one of two starting concepts to further examine and develop. Recognizing the importance of early childhood disaster education and that folklore is a valuable medium for early childhood education, the researchers focused on examining the use of folklore for early childhood disaster education.

As a result of this framework, the concepts that were formed, which the researchers proposed to discuss conceptually, included: 


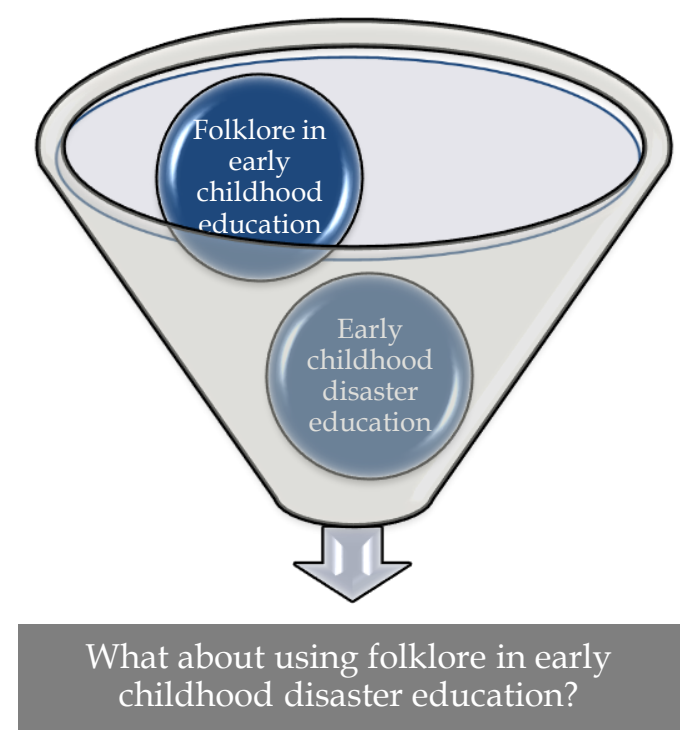

Figure 1: Conceptual Framework

\section{Methodology}

What about using folklore in early childhood disaster education? This is the emerging question for this conceptual paper. The researchers explored this question and built a hypothetical concept via literature research and critical thinking.

A conceptual paper is a powerful means of theory building (Jaakkola, 2020). Conceptual review papers can theoretically enrich the field by reviewing extant knowledge, noting concerns and inconsistencies, identifying important gaps in knowledge, key insights, and proposing agendas for future research (Hulland, 2020). The result of this process is a theoretical contribution that refines, reconceptualizes, or even replaces existing ways of viewing a phenomenon.

This conceptual paper is the base study for the researchers' larger empirical study on folklore for early childhood disaster education. Conceptual papers bridge existing theories in interesting ways, link work across disciplines, provide multilevel insights, and broaden the scope of our thinking; another important consideration is the need to create rational and detailed arguments about these connections, rather than only testing them (Gilson \& Goldberg, 2015).

In this conceptual paper, arguments are not derived in the conventional sense from empirical data, but involve assimilating and integrating information in the form of concepts and hypotheses that have been formed beforehand. Researchers examined previous empirical studies on the use of folklore for disaster education, then built concepts and theories based on the results of these previous studies.

The discussion and analysis of this conceptual paper used one of four templates for conceptual papers offered by Jaakkola (2020). The four templates are Theory Synthesis, Theory Adaptation, Typology and Model. Due to the respective aims, approach for using theories and contribution potential, this paper employs the Theory Synthesis as the template. 
A theory synthesis paper offers conceptual convergence through several hypotheses or sources of literature. These papers provide a new or improved view of a concept or phenomenon through a unique linking of previously unconnected or incompatible parts. According to MacInnis (2011), summarizing helps researchers by encapsulating, digesting, and reducing what is known to a more concise and manageable area of study. The integration helps to enable researchers to see a concept or phenomenon in a new way by transforming previous findings and theory into a novel higher-order perspective that links phenomena which may have been previously considered distinct (MacInnis, 2011). Such papers may also explore the conceptual underpinnings of an emerging theory or explain conflicting research findings by providing a more parsimonious explanation that pulls disparate elements into a more coherent whole.

To explore the use of folklore for early childhood disaster education, the researchers started by examining concepts of disaster education in early childhood education and folklore for early childhood education. These two concepts became the focus for further investigation. Then, the researchers investigated the focal phenomenon that is not adequately addressed in the existing research. The focal phenomenon was the use of folklore stories for early childhood education. The researchers identified differing conceptualizations of that phenomenon by analyzing literature that researchers gathered from Google Scholar using the keywords folklore disaster and folktale disaster. The studies observed did not specifically discuss the level of early childhood. The researchers examined the patterns, resemblances and regularities in the observed premises, looked for an explanation from the theoretical framework, and then finally concluded the study.

As a result of this framework, the following concepts were formed, which the researchers proposed to discuss conceptually:

\section{What about using folklore in early childhood disaster education?}

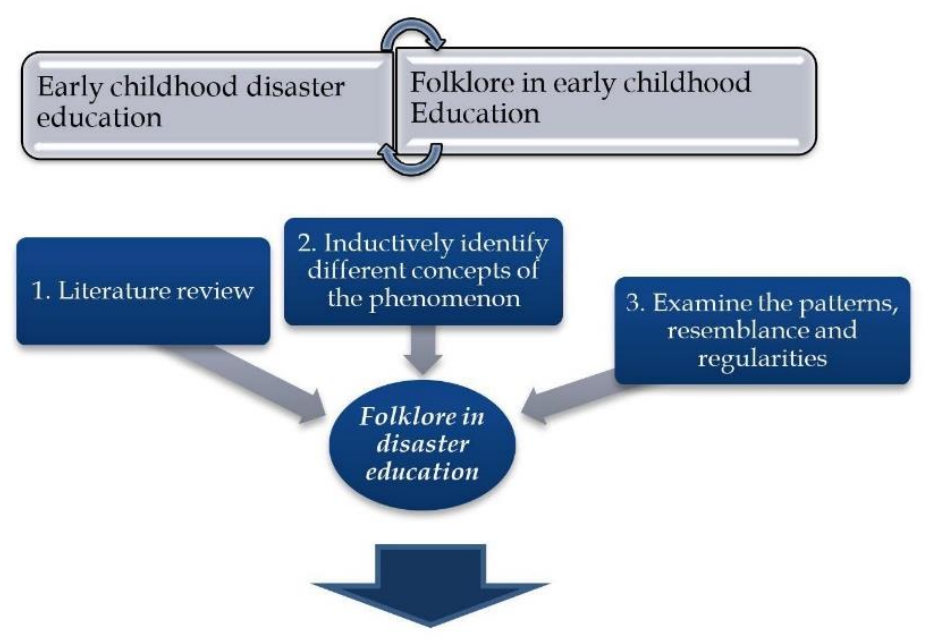

Synthetizing theory of the use folklore in early childhood disaster education

Figure 2. Methodology 


\section{Findings and Discussions}

Folklore has acquired considerable popularity among community-based DRR practitioners as one source of local knowledge for disaster mitigation (Mercer et al., 2012). Throughout this study, the researchers gathered and identified concepts from previous studies on the use of folklore for disaster prevention, preparedness, response, and disaster education programs. These gathered articles are not unique to early childhood education, while there also did not appear to be any specific research into the use of folklore in education in early childhood crises. This resulted in an expansion of the scope of existing research. The researchers searched for published Google Scholar studies using the keywords: folklore disaster education, folklore disaster mitigation, folklore volcano mitigation, folklore tsunami mitigation, folklore earthquake mitigation, folklore climate change, folklore environment, and folklore indigenous knowledge disaster.

Fifteen articles were found that discussed natural disasters and folklore. Of the fifteen documents, only two addressed education, and even these were not comprehensive. The articles were reviewed before the relevant concepts were described inductively. Three key concepts emerged from the mentioned literature, namely: 1) the disaster risk management that has six subgroup concepts; 2) disaster recovery and resilience that consists of two subgroup concepts; 3) indigenous knowledge and science that consists of two subgroup concepts.
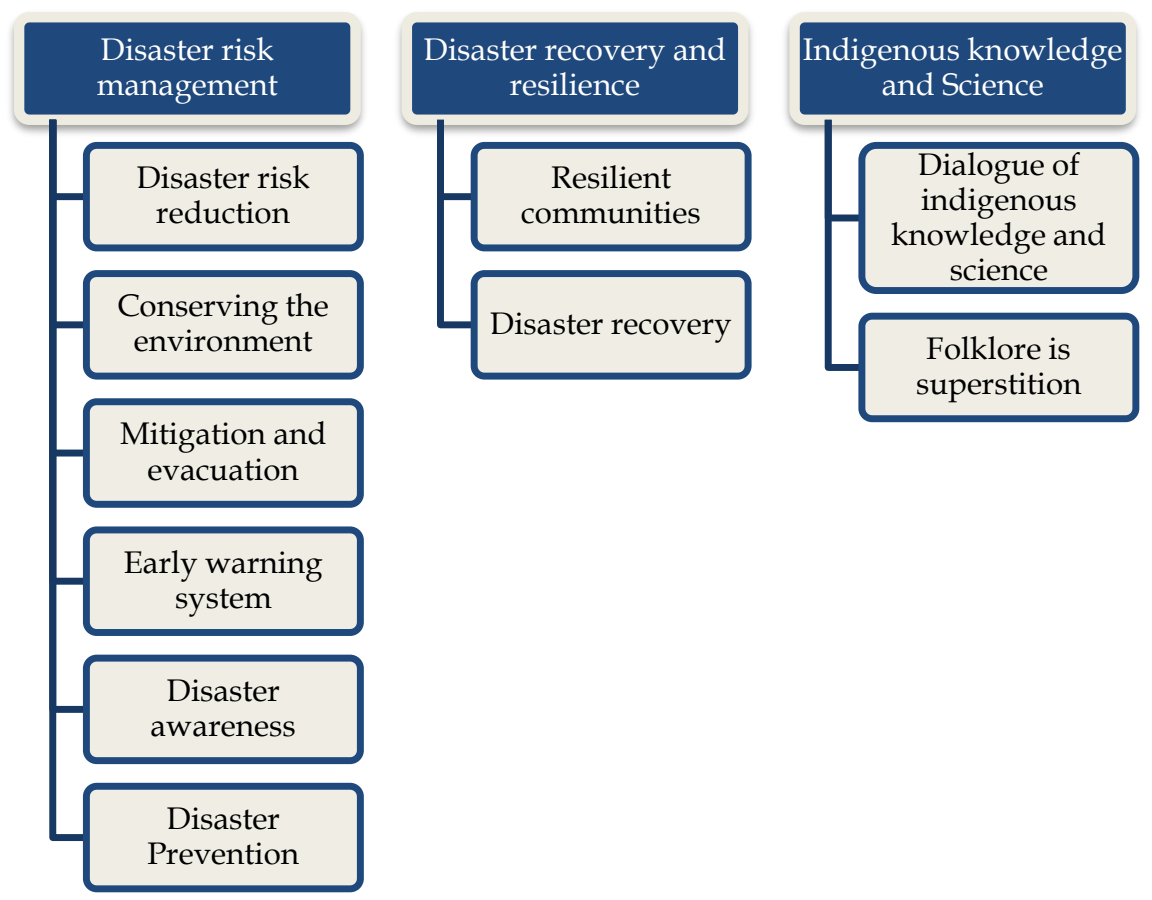

Figure 3. Emerging Concepts

\subsection{Disaster Risk Management}

There are seven articles on folklore that discuss disaster management-three articles from Indonesia, two India, one from the USA and another from Japan.

Gadeng, Maryani and Rohmat (2018) explored the indigenous knowledge Smong (folklore) in the community of Simeulue. Qualitative methods were used, 
including data gathering using in-depth questioning, participatory evaluation, analysis of the documentary and literature. The study revealed that the indigenous knowledge of Smong is a tsunami early warning system introduced by the Simeulue community in the forms of manafi-nafi (folklore), mananga-nanga (a cradle song often used to calm a baby to sleep) and nandong (humming). During the 2004 Tsunami, Smong helped save uncountable lives on Simeleu Island. The death toll on the island of Simeleu was just seven people, while on the island of Aceh, which was close by, the death toll reached 170,000.

Sukmawan and Setyowati (2017) examined Indonesian folklore stories that include environmental messages, and explores the understanding of high school English teachers in using Indonesian folklore to teach language. Content analysis and interviews were used to assess the applicability and suitability of folklore for foreign language lessons. They collected 17 different Indonesian folklores with messages about the environment, either implicitly or explicitly. The messages are: tragedy occurs due to the ignorance and violence of humans against nature, and it is the man himself who can keep the disaster from occurring. Folklore help the teacher prepare students to read, speak and write foreign languages; develop students' knowledge of environmental protection; improve cultural literacy; foster positive behavior, and practice critical thinking.

Troll et al. (2015) investigated the local climate at the Merapi volcano and combined this knowledge with recent developments in volcanology and volcanic control sciences. Researchers incorporated Merapi's historical, cultural, and scientific analysis in investigating Merapi folklore's geological background and obtained an enhanced underlying of Merapi's long-term behavior. Researchers also studied the folklore's significance in strengthening the local communities' resilience and responsiveness. Troll et al (2015) interpreted how the ancient people used the Merapi - Kraton - South Sea axis in local folklore to explain and rationalize the dynamic interplay of geological processes. Though now enveloped in mystery, these oral traditions may be considered an ancient disaster mitigation resource, which makes them possibly useful in helping to promote successful dialogue with a range of target parties and community groups along the slopes of the volcano.

Jha and Jha (2011) looked at the traditional knowledge of the Lepcha tribal community of Sikkim Himalayas on disaster management. Techniques for data collection include general observations over a 14-year period (1996-2010) and structured and unstructured interviews with indigenous Lepcha people. They assumed that the Lepcha people of Sikkim developed intricate philosophies further to understand the existence of disasters and their causes. These beliefs appear folkloristic as depicted in their stories and are based on sound principles that help guide actions and behaviors that can actively communicate and limit the impacts of disasters. Such philosophies also help people build close-knit social networks that make them more resilient when a tragedy affects them.

Pareek and Trivedi (2011) examined how people in the tribal societies in Rajasthan view and handle natural hazards and adverse weather conditions, including their methods for early warning and dealing with future events, as well as their views 
of their short- and long-term ecosystem impacts. Investigation approaches include analysis of the literature as a qualitative study, accompanied by informal conversations, open interviews, focus group interactions, workshops, cultural mappings and extensive interviews. The study showed that indigenous knowledge systems have allowed the different cultures in the region to live in harmony with their ecosystem for generations and that their traditional knowledge systems are valuable resources for conserving the environment and handling natural disasters.

Becker, Johnston, Lazrus, Crawford, and Nelson (2008) described the role of traditional knowledge and how it can assist in managing emergencies. They explored a specific case study in which a traditional Native American tale was paired with modern hazard prevention techniques to produce a tsunami hazard awareness film. They claimed that traditional knowledge can be successfully used to conduct disaster education and improve alert response. The video, entitled "Run to Higher Ground!" is an example, and indigenous communities and the public at large (both in the United States and internationally) have readily taken this as an instructional resource.

\subsection{Disaster Recovery and Resilience}

Four further articles discuss how folklore is useful for disaster recovery and resilience.

King, Goff, and Skipper (2007) assessed the range of Māori Environmental Knowledge (MEK) relating to natural hazards and discusses this specific information for management and mitigation in New Zealand. Researchers discussed myths, poems, place names and legends related to natural disasters through a thorough examination of documents in literature. Māori narratives and songs convey their vulnerabilities and resilience. Oral traditions, place names and environmental indices include important sources of expertise and awareness that are ignored. The study discovered despite the difficulties of using MEK, this environmental experience has some contributions to promoting the preparedness and prevention of contemporary natural hazards in New Zealand.

Cashman and Cronin (2008) investigated ways in which language, imagery, and metaphor explain volcanic events and may connect diverse cultures (both present and past) in their attempt to understand volcanic catastrophes. New Zealand Māori's have introduced volcanoes into the tribal and individual lineages. The study revealed Local tradition may provide a powerful community education resource and an important way of helping individuals and societies heal psychosocially from volcanic disasters.

Parsizadeh, Ibrion, Mokhtari, Lein, and Nadim (2015) examined how the socioeconomic environment and community values affected the understanding of earthquake risk and readiness of populations in Bam, Iran, before the major 2003 earthquake catastrophe. Data were obtained during two weeks in September 2013, nearly ten years after the Bam 2003 earthquake, using in-depth interviews with 30 earthquake survivors in the Bamand Baravat districts. They observed that Poems, folktales, oral traditions, and legends in Iran have considerable ability to alert the 
disasters and recall past seismic incidents and to help create and establish an "earthquake culture" in Iran.

Birkalan's study (2001) describes the accounts of experiences at Story House Masal Evi, Turkey, where researcher and teams used traditional folktales as coping resources to help children overcome the hardships of this massive tragedy. The storytelling events included about 35 children aged 3-15 years. The study suggested that fairytales are useful instruments for children to learn, socialize, and interact with their outside world, particularly in a post-earthquake crisis. Using folktales as narratives in their own right required making those activities intended for children. This also meant providing the children with an "imaginary" space to express the inexpressible and say the unthinkable.

\subsection{Indigenous Knowledge and Science}

Four articles were also found that referred to traditional knowledge and science for disaster mitigation.

King and Goff (2010) explored oral Māori traditions and how science explains the incidents portrayed in Māori tales. The study explained the crucial aspect that blends MEK and contemporary science to create new theories on massive environmental disruption along the coasts of Australia and New Zealand. The initiative would require not only recognition of other ways of knowing but also open dialogue with Māoris, and respect them to share their own stories.

Dube and Munsaka (2018) looked at the importance of indigenous knowledge to Zimbabwe's disaster risk management practices. Interviews and observations were used to collect data from 40 research participants from the district of Tsholotsho in Matabeleland, northern Zimbabwe. They noticed that local communities use the indigenous knowledge available to incorporate systemic steps as part of disaster risk management strategies. Nevertheless, this indigenous knowledge is often shunned by practitioners who say that indigenous knowledge lacks evidence, contextualized to particular populations and that knowledge cannot be confirmed scientifically.

Ludwin et al. (2007) examined local myths and folklore related to earthquakes, landslides, and tsunamis in Cascadian oral traditions (part of North America's northern Pacific coast) and Japanese written traditions, especially in the Edo area (now Tokyo). The study revealed the visual vocabulary of folklore and mythology could be a valuable addition to modern geological evidence to create a reliable historical record of volcanic development.

Orihara, Kamogawa, Noda \& Nagao (2019) investigated the Japanese folklore that says rare sightings of deep-sea fish are a reference to the earthquake. If this legend is proved real, the presence of deep-sea fish may be valuable knowledge for minimizing disasters. The researchers created a directory of newspaper accounts, scholarly papers, and the naval museum. They analyzed the details on the presence of deep-sea fish for the prevention of disasters. The study discovered the spatiotemporal link between the actions of deep-sea fish and the earthquakes was barely noticed from this study. Therefore, this Japanese myth is believed to be a superstition due to the illusory connection between the two incidents. 


\subsection{Theory Synthesizing}

These fifteen papers, explained above, contain three critical points:

1. Folklore is one type of indigenous or traditional knowledge that has been used since ancient times to warn about an impending catastrophe and to educate about mitigation.

2. Folklore is often believed to be the source of healing after a catastrophe has occurred.

3. Indigenous information such as that in a folklore needs to be combined and clarified by science to provide the provision.

Based on these findings, the questions remain concerning using folklore in early childhood disaster education. The researchers analyzed the trends, differences and inconsistencies of the reviewed literature to synthesize theory on using folklore in early childhood disaster education.

Traditional or indigenous or local knowledge is a system of experiential information gained through constant environmental observation and contact. Many communities still retain this kind of knowledge, and this knowledge can make a major contribution to emergency management for natural hazards. Traditional knowledge can help understand the nature of local hazards, suggest appropriate mechanisms for risk reduction and response, and even provide recovery options based on past experiences (Becker et al., 2008).

Local communities have continued to rely extensively on their systems of traditional knowledge in observing environmental and managing natural disasters. These communities have collectively created a large body of information on mitigation and prevention of disasters, early warning, preparedness and response, and recovery from disasters. This knowledge is acquired by observation and research and is also based on cumulative wisdom handed down from generation to generation (Grenier, 1998). Human reactions to hazards are affected by social, socioeconomic and cultural influences; societies evolve their unique approach. Consequently, a complete and unbiased vulnerability and risk assessment must take into account the cultural and social variables involved (Cashman \& Cronin, 2008; Donovan, Suryanto \& Utami, 2012; Harris \& Ripepe, 2007)

Traditional knowledge of disasters can assist in emergency mitigation by identifying unique characteristics of documented local hazards and, in some situations, by providing information on disaster response processes (Becker et al., 2008). Traditional wisdom in the context of oral histories, folklore, mythology, and songs could be a cross-cultural appealing and a powerful way to convey contemporary messages about the danger and possible disasters.

Hiwasaki, Luna, Syamsidik, and Shaw (2014) assured that local and indigenous knowledge are key to enhancing communities' resilience to hazards and climate change impacts. Nevertheless, scientists, practitioners, and policy-makers have yet to develop a structure of it. They believe that such knowledge needs to be integrated and clarified with science and technology before it can be used in disaster risk reduction policies, education, actions and adaptation to climate 
change. Integrating traditional and indigenous knowledge with science is an important mechanism that enables practitioners and scientists to carry out research and practices to improve communities' resilience. The integration also helps decision-makers to bring measures that enable these policies into practice. Such programs encourage the use of local and indigenous knowledge and enable communities to use their knowledge supplemented with outside knowledge to make educated choices on the implementation of their plans for mitigation and disaster risk reduction.

Mercer et al. (2012) suggest that local and "Western" knowledge should be incorporated and used in conjunction with each other to derive the best aspects of all understandings, in order to produce the most successful outcomes. They further propose that cautious community consultation and engagement is the best way to build solutions that accommodate this combination and thereby boost resilience. Local and indigenous knowledge that helps societies develop their resilience, which cannot be clarified or combined with science, is classified separately. Communities may continue to practice that knowledge, free from criticism from experts, politicians, and professionals (Hiwasaki et al., 2014).

Folklore has the immense potential to make a successful contribution to early childhood disaster education. Besides entertaining, folklore is a strong socialization and communication device that can mold and enhance traditions, convictions, values and attitudes (Cocks, 2013). However, traditional and indigenous knowledge has to be combined and clarified with science before it can be used in disaster risk management and climate change policies, education, and initiatives. There should be empirical evidence in the stories for using folklore in early childhood disaster education; children should not blindly believe anything that has not been proven to be right. Children need to know if a story that is being told might not be true or is unproven. Teachers and parents should be knowledgeable about the tale and the facts behind it, and therefore the folklore is indeed insightful and could teach children better to prevent, prepare, respond and recover after a disaster has occurred.

Below is an illustration of how the researchers underwent this systematic process until a conclusion was reached. 
Culture has a significant role to promote disaster prevention, preparedness and response (Bankoff et al., 2004; Donovan, 2010; Kutalunga, 2010; Jha \& Jha, 2011; Appleby-Arnold et al., 2018)

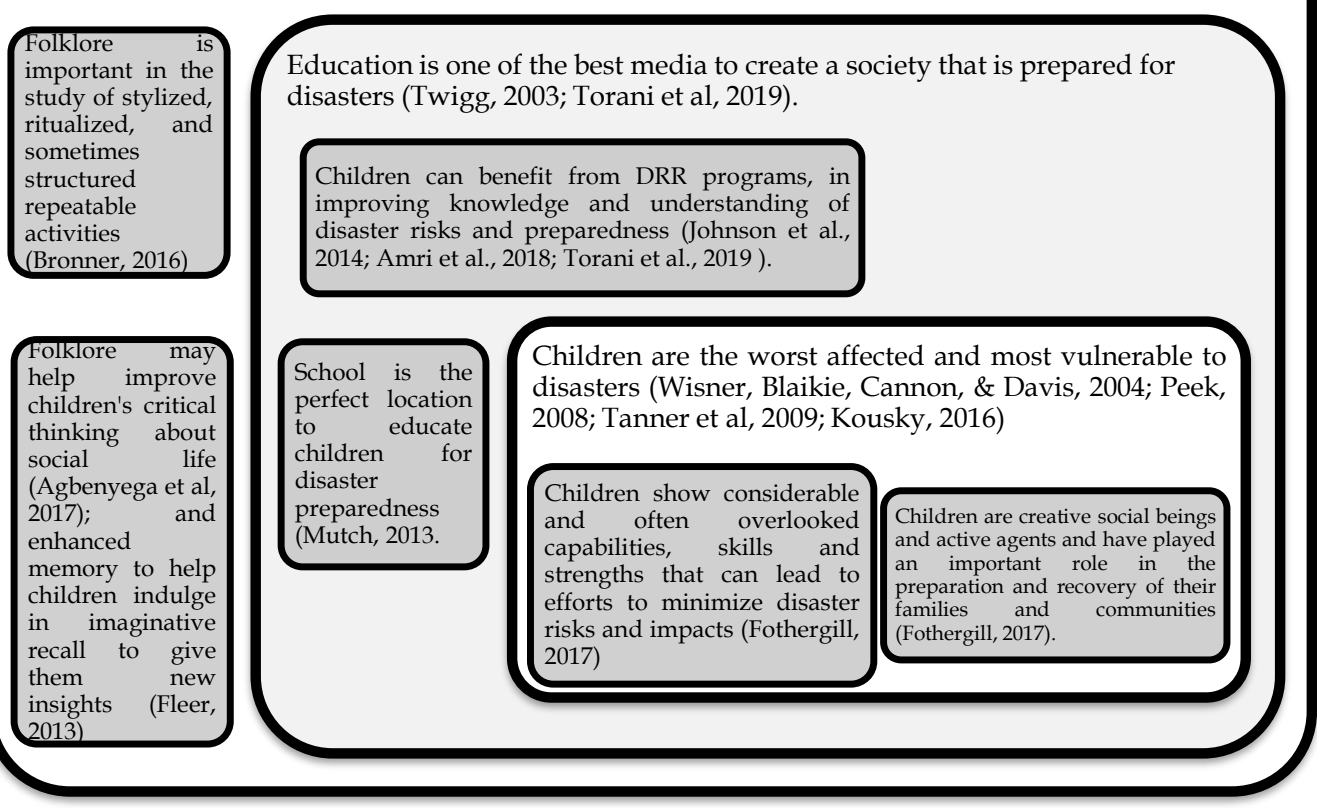

\section{GATHERED \& REVIEWED ARTICLES}

Folklore disaster education
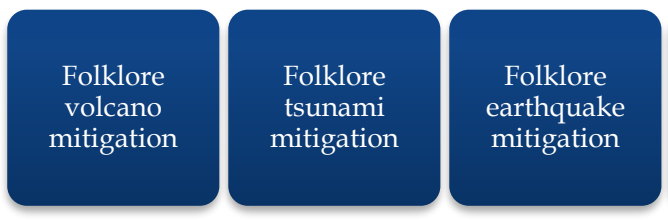

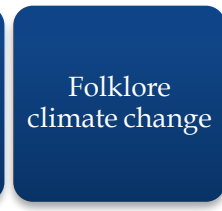

Folklore disaster mitigation

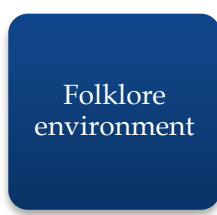

Folklore

indigenous

knowledge \&

Disaster

Analyze the patterns, parallels, and regularities of the fifteen collected literature

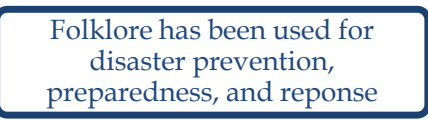

Folklore has been used for recovery and building resiliency

Folklore needs to be communicated with, integrated to, and clarified by science

\section{Synthesize Theory/Answering Question}

What about using folklore in early childhood disaster education?

Folklore has an enormous potential to make early childhood disaster education successful if it is also conveyed, incorporated and explained by science

Figure 4. Process of analysis and theory synthesizing 


\section{Conclusion}

Traditional local knowledge, like folklore, is found to be a strong communication tool to help educate and mitigate disasters. In post-disaster circumstances, many people also use folklore to help the community rebuild and become more resilient. However, scholars believe that if folklore is not conveyed, combined and explained with evidence, it functions less efficiently. This paper looks at the probability of using folklore in early childhood disaster education. Researchers found that folklore is potentially a promising platform for educating young children about disaster prevention, preparedness, response and recovery. However, science should also help to convey, incorporate and clarify the texts and contexts of the folklore. This work used systematic analysis methods to examine the existing information. There are some drawbacks in the study design; from the papers studied, many do not address the whole matter comprehensively; others are often based solely on literature reviews, while others are empirical studies containing just a few samples. The number of papers found is also very limited. More detailed and well-structured studies are needed for the continuation of this work. This research serves as a strong base for future investigation into how to make folklore a successful resource for use in early childhood disaster education.

\section{Acknowledgment}

We thank the Center of Research and Publication (PUSLITPEN-LP2M), UIN Syarif Hidayatullah Jakarta, Indonesia and the Ministry of Religious Affairs, Republic of Indonesia for the financial support provided to conduct this research. We would especially like to thank Adam Batten for his review and informative feedback throughout the production of this writing.

\section{References}

Agbenyega, J. S., Tamakloe, D. E., \& Klibthong, S. (2017). Folklore epistemology: how does traditional folklore contribute to children's thinking and concept development? International Journal of Early Years Education, 25(2), 112-126. https://doi.org/10.1080/09669760.2017.1287062

Agosto, D. E. (2016). Why Storytelling Matters: Unveiling the Literacy Benefits of Storytelling. Children and Libraries, 14(2), 21. https://doi.org/10.5860/cal.14n2.21

Amri, A., Haynes, K., Bird, D. K., \& Ronan, K. (2018). Bridging the divide between studies on disaster risk reduction education and child-centred disaster risk reduction: a critical review. Children's Geographies, 16(3), 239-251. https://doi.org/10.1080/14733285.2017.1358448

Ani, P. A. B., Daquio, C. R. O., \& Aquino, A. P. (2015). Republic Act 10121: An Approach in Strengthening Disaster Risk Reduction and Management in the Philippines. Retrieved August 3, 2020, from https://ap.fftc.org.tw/article/838

Appleby-Arnold, S., Brockdorff, N., Jakovljev, I., \& Zdravković, S. (2018). Applying cultural values to encourage disaster preparedness: Lessons from a low-hazard country. International Journal of Disaster Risk Reduction, 31, 37-44. https://doi.org/10.1016/j.ijdrr.2018.04.015

Bankoff, G. (2013). Mapping Vulnerability. Routledge. https://doi.org/10.4324/9781849771924

Becker, J., Johnston, D., Lazrus, H., Crawford, G., \& Nelson, D. (2008). Use of traditional knowledge in emergency management for tsunami hazard. Disaster Prevention and Management: An International Journal, 17(4), 488-502. https://doi.org/10.1108/09653560810901737 
Ben-Amos, D. (1971). Toward a Definition of Folklore in Context. The Journal of American Folklore, 84(331), 3. https://doi.org/10.2307/539729

Ben-Amos, D. (2014). A Definition of Folklore: A Personal Narrative. Estudis de Literatura Oral Popular / Studies in Oral Folk Literature, (3), 9. https://doi.org/10.17345/elop20149-28

Bosschaart, A., van der Schee, J., Kuiper, W., \& Schoonenboom, J. (2016). Evaluating a flood-risk education program in the Netherlands. Studies in Educational Evaluation, 50, 53-61. https://doi.org/10.1016/j.stueduc.2016.07.002

Bronner, S. J. (2011). Explaining Traditions: Folk Behavior in Modern Culture. Lexington: University Press of Kentucky.

Bronner, S. J. (2019). Toward a definition of folklore in practice. In The Practice of Folklore (pp. 64-82). University Press of Mississippi. https:// doi.org/10.2307/j.ctvkwnnvd.6

Bryant, R. A., Gibbs, L., Gallagher, H. C., Pattison, P., Lusher, D., MacDougall, C., ... Forbes, D. (2018). Longitudinal study of changing psychological outcomes following the Victorian Black Saturday bushfires. Australian \& New Zealand Journal of Psychiatry, 52(6), 542-551. https://doi.org/10.1177/0004867417714337

Cashman, K. V., \& Cronin, S. J. (2008). Welcoming a monster to the world: Myths, oral tradition, and modern societal response to volcanic disasters. Journal of Volcanology and Geothermal Research, 176(3), 407-418. https://doi.org/10.1016/j.jvolgeores.2008.01.040

Cassell, J. (2004). Towards a model of technology and literacy development: Story listening systems. Journal of Applied Developmental Psychology, 25(1), 75-105. https://doi.org/10.1016/j.appdev.2003.11.003

Cocks, D. (2013). Ecohumanism and Other Stories. In Global Overshoot (pp. 349-375). New York, NY: Springer New York. https:/ / doi.org/10.1007/978-1-4614-6265-1_6

Donovan, K. (2010). Doing social volcanology: exploring volcanic culture in Indonesia. Area, 42(1), 117-126. https://doi.org/10.1111/j.1475-4762.2009.00899.x

Donovan, K., Suryanto, A., \& Utami, P. (2012). Mapping cultural vulnerability in volcanic regions: The practical application of social volcanology at Mt Merapi, Indonesia. Environmental Hazards, 11(4), 303-323. https://doi.org/10.1080/17477891.2012.689252

Dube, E., \& Munsaka, E. (2018). The contribution of indigenous knowledge to disaster risk reduction activities in Zimbabwe: A big call to practitioners. Jàmbá: Journal of Disaster Risk Studies, 10(1). https:// doi.org/10.4102/jamba.v10i1.493

Duffy, N. (2014). Opportunities for disaster resilience learning in the Australian curriculum. Australian Journal of Emergency Management, 29(1), 12-16. https://doi.org/10.1007/s11069-016-2435-5

Eisman, A. B., Kilbourne, A. M., Ngo, Q., Fridline, J., Zimmerman, M. A., Greene, D., \& Cunningham, R. M. (2020). Implementing a State-Adopted High School Health Curriculum: A Case Study. Journal of School Health, 90(6), 447-456. https://doi.org/10.1111/josh.12892

Faber, M. H., Giuliani, L., Revez, A., Jayasena, S., Sparf, J., \& Mendez, J. M. (2014). Interdisciplinary Approach to Disaster Resilience Education and Research. Procedia Economics and Finance, 18, 601-609. https://doi.org/10.1016/S2212-5671(14)00981-2

Fleer, M. (2013). Affective Imagination in Science Education: Determining the Emotional Nature of Scientific and Technological Learning of Young Children. Research in Science Education, 43(5), 2085-2106. https://doi.org/10.1007/s11165-012-9344-8

Flewitt, R. (2017). Equity and diversity through story: A multimoda perspective. In T. Cremin, R. Flewitt, B. Mardell, \& J. Swan (Eds.), Storytelling in early childhood: enriching language, literacy and classroom culture (pp. 150-167). Abingdon, Oxon: Routledge. 
Fothergill, A. (2017). Children, Youth, and Disaster. In Oxford Research Encyclopedia of Natural Hazard Science. Oxford University Press. https://doi.org/10.1093/acrefore/9780199389407.013.23

Gadeng, A. N., Maryani, E., \& Rohmat, D. (2018). The Value of Local Wisdom Smong in Tsunami Disaster Mitigation in Simeulue Regency, Aceh Province. IOP Conference Series: Earth and Environmental Science, 145, 012041. https://doi.org/10.1088/17551315/145/1/012041

Gibbs, L., Nursey, J., Cook, J., Ireton, G., Alkemade, N., Roberts, M., ... Forbes, D. (2019). Delayed Disaster Impacts on Academic Performance of Primary School Children. Child Development, 90(4), 1402-1412. https://doi.org/10.1111/cdev.13200

Gilson, L. L., \& Goldberg, C. B. (2015). Editors' Comment. Group \& Organization Management, 40(2), 127-130. https://doi.org/10.1177/1059601115576425

Gulay, H. (2010). An earthquake education program with parent participation for preschool children. Educational Research and Reviews, 5(10), 624-630.

Gunnestad, A., \& Thwala, S. (2011). Resilience and religion in children and youth in Southern Africa. International Journal of Children's Spirituality, 16(2), 169-185. https://doi.org/10.1080/1364436X.2011.580726

Harris, A. J. L., \& Ripepe, M. (2007). Regional earthquake as a trigger for enhanced volcanic activity: Evidence from MODIS thermal data. Geophysical Research Letters, 34(2), L02304. https://doi.org/10.1029/2006GL028251

Harvilahti, L. (2004). Folklore and Oral Tradition. Oral Tradition, 18(2), 200-202. https://doi.org/10.1353/ort.2004.0065

Haynes, K., \& Lassa, J. (2010). Child centred disaster risk reduction and climate change adaptation: roles of gender and culture in Indonesia.

Hiwasaki, L., Luna, E., Syamsidik, \& Shaw, R. (2014). Process for integrating local and indigenous knowledge with science for hydro-meteorological disaster risk reduction and climate change adaptation in coastal and small island communities. International Journal of Disaster Risk Reduction, 10, 15-27. https://doi.org/10.1016/j.ijdrr.2014.07.007

Hulland, J. (2020). Conceptual review papers: revisiting existing research to develop and refine theory. AMS Review, 10(1-2), 27-35. https://doi.org/10.1007/s13162-02000168-7

Izadkhah, Y. O., \& Hosseini, M. (2005). Towards resilient communities in developing countries through education of children for disaster preparedness. International $\begin{array}{llll}\text { Journal of Emergency } & 138 .\end{array}$ https://doi.org/10.1504/IJEM.2005.007355

Jaakkola, E. (2020). Designing conceptual articles: four approaches. AMS Review, 10(1-2), 18-26. https://doi.org/10.1007/s13162-020-00161-0

Jha, V., \& Jha, A. (2011). Traditional knowledge on disaster management: A preliminary study of the Lepcha community of Sikkim, India. Indian Journal of Traditional Knowledge, 10(1), 173-182.

Johnson, V. A., Ronan, K. R., Johnston, D. M., \& Peace, R. (2014). Evaluations of disaster education programs for children: A methodological review. International Journal of Disaster Risk Reduction, 9, 107-123. https:/ / doi.org/10.1016/j.ijdrr.2014.04.001

King, D. N., \& Goff, J. R. (2010). Benefitting from differences in knowledge, practice and belief: Māori oral traditions and natural hazards science. Natural Hazards and Earth System Sciences, 10(9), 1927-1940. https:// doi.org/10.5194/nhess-10-1927-2010

King, D. N., Goff, J., \& Skipper, A. (2007). Māori environmental knowledge and natural hazards in Aotearoa-New Zealand. Journal of the Royal Society of New Zealand, 37(2), 59-73. https://doi.org/10.1080/03014220709510536 
Kousky, C. (2016). Impacts of natural disasters on children. Future of Children. https:// doi.org/10.1353/foc.2016.0004

Kulatunga, U. (2010). Impact of culture towards disaster risk reduction. International Journal of Strategic Property Management, 14(4), 304-313. https://doi.org/10.3846/ijspm.2010.23

Lenox, M. F. (2000). Storytelling for Young Children in a Multicultural World. Early Childhood Education Journal, 28, 97-103. https://doi.org/https://doi.org/10.1023/A:1009599320835

Louise, G. (1998). Working with Indigenous Knowledge: A Guide for Researchers I IDRC International Development Research Centre. Retrieved from https://www.idrc.ca/en/book/working-indigenous-knowledge-guideresearchers

Ludwin, R. S., Smits, G. J., Carver, D., James, K., Jonientz-Trisler, C., McMillan, A. D., ... Wray, J. (2007). Folklore and earthquakes: Native American oral traditions from Cascadia compared with written traditions from Japan. Geological Society, London, Special Publications, 273(1), 67-94. https://doi.org/10.1144/GSL.SP.2007.273.01.07

MacInnis, D. J. (2011). A Framework for Conceptual Contributions in Marketing. Journal of Marketing, 75(4), 136-154. https:// doi.org/10.1509/jmkg.75.4.136

Mardell, B., \& Kucirkova. (2017). Promoting democratic classroom communities throung storytelling and story acting. In T. Cremin, R. Flewitt, B. Mardell, \& J. Swan (Eds.), Storytelling in early childhood: enriching language, literacy and classroom culture (pp. 169185). Abingdon, Oxon: Routledge.

Maureen, I. Y., van der Meij, H., \& de Jong, T. (2018). Supporting Literacy and Digital Literacy Development in Early Childhood Education Using Storytelling Activities. International Journal of Early Childhood, 50(3), 371-389. https://doi.org/10.1007/s13158-018-0230-z

Mercer, J., Gaillard, J. C., Crowley, K., Shannon, R., Alexander, B., Day, S., \& Becker, J. (2012). Culture and disaster risk reduction: Lessons and opportunities. Environmental Hazards, 11(2), 74-95. https:/ / doi.org/10.1080/17477891.2011.609876

Mileti, D. (1995). Public hazards communication and education: the state of the art. 1-12.

Mulyasari, F., Takeuchi, Y., \& Shaw, R. (2011). Chapter 7 Implementation Tools for Disaster Education. https://doi.org/10.1108/S2040-7262(2011)0000007013

Mutch, C. (2014). The role of schools in disaster preparedness, response and recovery: what can we learn from the literature? Pastoral Care in Education, 32(1), 5-22. https://doi.org/10.1080/02643944.2014.880123

Nicolopoulou, A., Cortina, K. S., Ilgaz, H., Cates, C. B., \& de Sá, A. B. (2015). Using a narrative- and play-based activity to promote low-income preschoolers' oral language, emergent literacy, and social competence. Early Childhood Research Quarterly, 31, 147-162. https://doi.org/10.1016/j.ecresq.2015.01.006

Norris, F. H., Friedman, M. J., Watson, P. J., Byrne, C. M., Diaz, E., \& Kaniasty, K. (2002). 60,000 Disaster Victims Speak: Part I. An Empirical Review of the Empirical Literature, 1981-2001. Psychiatry: Interpersonal and Biological Processes, 65(3), 207-239. https://doi.org/10.1521/psyc.65.3.207.20173

Olajide, S. B. (2010). Folklore and Culture as Literacy Resources for National Emancipation. International Education Studies, 3(2), 200-205. https://doi.org/10.5539/ies.v3n2p200

Pareek, A., \& Trivedi, P. C. (2011). Cultural values and indigenous knowledge of climate change and disaster prediction in Rajasthan, India. Indian Journal of Traditional Knowledge, 10(1), 183-189.

Parsizadeh, F., Ibrion, M., Mokhtari, M., Lein, H., \& Nadim, F. (2015). Bam 2003 earthquake disaster: On the earthquake risk perception, resilience and earthquake 
culture - Cultural beliefs and cultural landscape of Qanats, gardens of Khorma trees and Argh-e Bam. International Journal of Disaster Risk Reduction, 14, 457-469. https://doi.org/10.1016/j.ijdrr.2015.09.011

Peek, L. (2008). Children and Disasters: Understanding Vulnerability, Developing Capacities, and Promoting Resilience-An Introduction. In Children, Youth and Environments (Vol. 18). Retrieved from http://www.colorado.edu/journals/cye.

Proulx, K., \& Aboud, F. (2019). Disaster risk reduction in early childhood education: Effects on preschool quality and child outcomes. International Journal of Educational Development, 66, 1-7. https://doi.org/10.1016/j.ijedudev.2019.01.007

Rahiem, M. D. H., Abdullah, N. S. M., \& Krauss, S. E. (2020). Moral Education through Dramatized Storytelling: Insights and Observations from Indonesia Kindergarten Teachers. International Journal of Learning, Teaching and Educational Research, 19(3), 475-490. https://doi.org/10.26803/ijlter.19.3.26

Rahiem, M. D. (2018). Faith and Disaster Resilience: What can Islamic Education Teach Children to Help Prepare Them for A Disaster? TARBIYA: Journal of Education in Muslim Society, 5(2), 178-192. https://doi.org/10.15408/tjems.v5i2.9964

Rahim, H., \& Rahiem, M. D. H. (2013). The Use of Stories as Moral Education for Young Children. International Journal of Social Science and Humanity, 2(6), 454-458. https://doi.org/10.7763/IJSSH.2012.V2.145

Ronan, K. R., Alisic, E., Towers, B., Johnson, V. A., \& Johnston, D. M. (2015). Disaster Preparedness for Children and Families: a Critical Review. Current Psychiatry Reports, 17(7), 58. https://doi.org/10.1007/s11920-015-0589-6

Sharpe, J., \& Kelman, I. (2011). Improving the disaster-related component of secondary school geography education in England. International Research in Geographical and Environmental Education, 20(4), 327-343. https://doi.org/10.1080/10382046.2011.619810

Shreve, C., Fordham, M., Anson, S., Watson, H., Hagen, K., Kush, W., ... Karanci, N. (2014). Report on risk Perception and Preparedness. Report on risk Perception and Preparedness. http://www.academia.edu/download/36213263/Deliverable_D1.1_FINAL.pdf

Shultz, J. M. (2014). Perspectives on disaster public health and disaster behavioral health integration. Disaster Health, 2(2), 69-74. https://doi.org/10.4161/dish.24861

Somasundaram, D. J., \& van de Put, W. A. C. M. (2006). Management of trauma in special populations after a disaster. The Journal of Clinical Psychiatry, 67 Suppl 2, 64-73. Retrieved from http://www.ncbi.nlm.nih.gov/pubmed/16602818

Sukmawan, S., \& Setyowati, L. (2017). Environmental Messages as Found in Indonesian Folklore and Its Relation to Foreign Language Classroom. Arab World English Journal, 8(1), 298-308. https://doi.org/10.24093/awej/vol8no1.21

Tanner, T., Lazcano, J., Lussier, K., \& Polack, E. (2009). Children, climate change and disasters: An annotated bibliography. Retrieved from http://mobile.opendocs.ids.ac.uk/opendocs/handle/123456789/2373

Thambu, N. (2017). Storytelling and Story Reading: A Catalyst for Inculcate Moral Values and Ethics among Preschoolers. International Journal of Academic Research in Business and Social Sciences, 7(6). https://doi.org/10.6007/IJARBSS/v7-i6/3143

Thompson, M. (2011). Developing moral values in children: Observations from a preschool. IFE PsychologIA, 19(2), 394-411. https://doi.org/10.4314/ifep.v19i2.69584

Tomasello, M. (2009). The question of chimpanzee culture, plus postscript. In K. N. Laland \& G. Galef (Eds.), The question of animal culture (pp. 198-221). Harvard University Press. 
Torani, S., Majd, P., Maroufi, S., Dowlati, M., \& Sheikhi, R. (2019). The importance of education on disasters and emergencies: A review article. Journal of Education and Health Promotion, 8(1), 85. https://doi.org/10.4103/jehp.jehp_262_18

Troll, V. R., Deegan, F. M., Jolis, E. M., Budd, D. A., Dahren, B., \& Schwarzkopf, L. M. (2015). Ancient oral tradition describes volcano-earthquake interaction at merapi volcano, indonesia. Geografiska Annaler: Series A, Physical Geography, 97(1), 137-166. https://doi.org/10.1111/geoa.12099

Tsai, M.-H., Wen, M.-C., Chang, Y.-L., \& Kang, S.-C. (2015). Game-based education for disaster prevention. AI \& SOCIETY, 30(4), 463-475. https://doi.org/10.1007/s00146014-0562-7

Twigg, J. (2003). The Human Factor in Early Warnings: Risk Perception and Appropriate Communications. In Early Warning Systems for Natural Disaster Reduction (pp. 19-26). Berlin, Heidelberg: Springer Berlin Heidelberg. https://doi.org/10.1007/978-3-64255903-7_4

United Nations. (2005). International Strategy for Disaster Reduction Hyogo Framework for Action 2005-2015: Building the Resilience of Nations. World Conference on Disaster Reduction (A/CONF.206/6). https://doi.org/10.1017/CBO9781107415324.004

United Nations Children's Emergency Fund. (2011). 2011 Humanitarian action for children: Building resilience. In Unicef. Retrieved from http://scholar.google.com/scholar?hl=en\&btnG=Search\&q=intitle:Humanitarian+ Action+for+Children+building+resilience\#0

Winser, B., Blaikie, P., Cannon, T., Davis, I., Torres, R., Azócar, G., ... Shirley, W. L. (2004). At Risk: Natural Hazards, People's Vulnerability and Disasters - Piers Blaikie, Terry Cannon, Ian Davis, Ben Wisner - Google Books. Geoforum. https://doi.org/10.1016/J.GEOFORUM.2014.12.013

Woodard, J. (2005). Head, Heart and Hands: Waldorf Education. Journal of Curriculum and Pedagogy, 2(2), 84-85. https://doi.org/10.1080/15505170.2005.10411551 